\title{
EXTENDING THE TRADITIONAL CLASSROOM THROUGH ONLINE DISCUSSION: THE ROLE OF STUDENT MOTIVATION*
}

\author{
KUI XIE \\ TERESA K. DEBACKER \\ CATHERINE FERGUSON \\ University of Oklahoma
}

\begin{abstract}
Two studies addressed students' motivation and participation in an online discussion board which was part of a traditional lecture-based course. The discussion board represented an external communication resource to extend the learning activities beyond the classroom. Self-Determination Theory was used as the theoretical framework to investigate: (a) how students' participation in online discussion related to their intrinsic motivation and attitude toward the class; b) how students' intrinsic motivation changed over time; and c) what factors students noted as responsible for the changes in their motivation level. A total of 123 undergraduate students participated in online discussion as a normal part of their instructional technology class. The results showed that students' participation was related to their intrinsic motivation, but not to their computer/internet skills. Over time, students' intrinsic motivation for participating in online discussion dropped steadily. Student-reported reasons for the motivation changes are discussed.
\end{abstract}

\section{INTRODUCTION}

The online discussion board, an asynchronous computer-mediated communication system that provides anytime/anyplace communication through computer

*A version of this article was presented at the 2005 conference of the American Educational Research Association, Montreal, Canada. 
networks (Benbunan-Fich \& Hiltz, 1999), has been widely used in distance education. Increasingly, it is being integrated into on-site educational settings as well, to extend learning activities beyond the traditional classroom time and space. The online discussion board has the potential to facilitate learning communities (Duemer et al., 2002) and to promote collaborative learning (Horton, 2000; Murphy, 2004) among students outside of the classroom. Via the online discussion board, class members can "meet and form study groups virtually, establish professional relationships, debate class topics, and act as a class would if held continually" (Spencer \& Hiltz, 2003).

Online discussion systems provide a variety of benefits for learners. For example, they can provide learners with varying oral language skills more equal opportunities to participate in discussion (Zhang \& Mu, 2003) and can facilitate the use of language that is lexically and syntactically more formal and complex than that found in face-to-face discussion (Warschauer, 1996). The electronic system can keep a text-based digital record of thoughts, concepts, plans, answers, and strategies which have been addressed during the online discussion (Hara, Bonk, \& Angeli, 2000). Students can reflect on their thoughts in a more formal format, which may foster their metacognitive (McDuffie \& Slavit, 2003) and critical thinking (Jeong, 2003) skills.

However, the benefits of online discussion are not guaranteed, and the research literature shows that factors such as low levels of student participation (Thomas, 2002) can erode the quality of online discussion. Students' motivation to participate in online discussion activity is an important factor in the success of this method and warrants investigation.

Much research has been done on the usability of online discussion (Jeong, 2003; Ronteltap \& Eurelings, 2002; Yildiz \& Bichelmeyer, 2003; Zhang \& Mu, 2003), the attitudes and perceptions of learners in online environments (Howland \& Moore, 2002), and the relationship of learning style to the effectiveness of online learning (Aragon, Johnson, \& Shaik, 2002; Diaz \& Cartnal, 1999; Neuhauser, 2002). Yet there is little research that directly addresses students' motivation related to their participation in online discussion. This article introduces two mixed-method studies designed to investigate the relationship among students' intrinsic motivation for participating in online discussion and other issues related to participating in an online discussion board. The following questions guided these two studies:

1. How is students' participation in online discussion related to their intrinsic motivation for online discussion and attitude toward the class in general?

2. Does students' intrinsic motivation change over the duration of the class?

3. What factors do students note as responsible for changes in their motivation level?

4. What are the instructors' perspectives about the inclusion of the online discussion? 


\section{THEORETICAL BACKGROUND}

These two studies used Self-Determination Theory (SDT) (Deci \& Ryan, 1985) as a theoretical framework to investigate students' motivation to participate in online discussions. Self-determination theory (SDT) proposes that a student's motivation for any given task can range from intrinsic to extrinsic (Deci \& Ryan, 1985). Intrinsic motivation is defined as "the doing of an activity for its inherent satisfactions rather than for some separable consequence" (Ryan \& Deci, 2000b). It is "the innate propensity to engage one's interests and to exercise one's capacities and, in doing so, to seek out and master optimal challenges" (Deci \& Ryan, 1985). When intrinsically motivated, a person is moved to act for the fun or challenge entailed rather than because of external stimuli, pressures, or rewards. People who are intrinsically motivated usually show "more interest, excitement, and confidence, which in turn are manifest both as enhanced performance, persistence, and creativity, and as heightened vitality, self-esteem, and general well-being" (Deci \& Ryan, 2000). On the other hand, when students engage in tasks in order to earn incentives such as rewards, positive feedback, or good grade, or to avoid punishment or unpleasant consequences, they are said to be extrinsically motivated (Ryan \& Deci, 2000b).

SDT proposes that motivation can vary greatly in the degree to which it is autonomous (Ryan \& Deci, 2000a) and identifies four different types of extrinsic motivation. Under external regulation students engage in the learning task solely to earn rewards or avoid punishments, and perceive that their behavior is under purely external control. Under introjected regulation students begin to experience a degree of self-control and may engage in the learning task to avoid guilt or to experience pride (i.e., internally determined rewards and punishments). With identified regulation students begin to feel that their behavior is internally controlled, and express personal valuing of the learning task. Finally, under integrated regulation, the most autonomous form of extrinsic motivation, the student feels that engaging in the learning task is congruent with his/her personal values and senses of self.

As suggested by this continuum, students who have high internal interest in learning tasks, or who perceive tasks as having high value or importance, and who feel that their behavior is highly self-determined, will perform in a manner similar to students who are intrinsically motivated. That is, with increasingly internal drive students might demonstrate greater persistence, more positive selfperceptions, and higher quality task engagement (Ryan \& Deci, 2000a).

\section{RECENT FINDINGS AND DISCUSSIONS}

Although recent studies related to utilizing online discussion in educational settings have not addressed students' motivation directly, there are relevant findings that can be interpreted under the framework of Self-Determination Theory. 
Since online discussion is a novel and unfamiliar form of class activity for many students, students' competence in using the online discussion tools becomes an important issue that may influence students' motivation to participate in the discussion. Howland and Moore (2002) found that using the features of a course management tool, such as the discussion board and chat room, proved to be challenging for novice computer users. When students feel incompetent using the system, they show much lower motivation and will seek other familiar methods (e.g., e-mail or telephone) to communicate with other students or the instructor. Therefore, before students can use online discussion tools to construct knowledge, they need to be taught how to use them, such as responding to messages, creating new discussion threads, and so on. With this support students will become comfortable and proficient using the environment (Benfield, 2002) leading to increased feeling of competence and motivation.

Interaction and communication are the main purposes for participating in online discussions. A successful online discussion should be well facilitated and guided so that students feel the discussion is not only informational, but also interesting. As long as students perceive that online discussion is a useful and valuable way to communicate and get information, their intrinsic motivation will be promoted and they will show more willingness to continue to participate in this type of discussion. In a moderated discussion group, the instructor-or someone elsewatches over the exchange of messages. This moderator may start or participate in discussions, provide timely feedback to difficult questions, identify the key issues remaining to be addressed, or make explicit suggestions for further development (Benfield, 2002; Horton, 2000). A good moderator also has to both stand back and let the participants play the main role in the discussion and also intervene to guide the discussion into useful directions. Because high quality facilitation increases the perceived value of online discussion, students may be more motivated to participate in online discussions which are well-facilitated.

Many studies also addressed the association of online discussion with course assessment. They found that students' participation in online discussion is often linked to extrinsic forms of motivation (Thomas, 2002) and linking student contributions in the online discussions to assessment has been a useful mechanism to improve student participation (Benfield, 2002). However, the association with course requirements might cause the discussion to be shallow and perfunctory (Howland \& Moore, 2002). Therefore, Thomas (2002) suggested that linking participation to assessment may be appropriate when the assessments were evaluated both quantitatively and qualitatively. Moreover, research suggested that most active and effective online discussions are highly purposeful and taskoriented (Benfield, 2002; Horton, 2000; Jeong, 2003; Ronteltap \& Eurelings, 2002). These discussions are more likely to be perceived by students as more valuable and, hence, more motivating. However, the tasks in these discussions may lead to feelings of being overly controlled which will reduce feelings of self-determination (Howland \& Moore, 2002; Liu, 2002). Therefore, the design 
of the online discussion may need to find a balance between task-oriented and self-directed approaches.

To investigate how these factors affect students' motivation in online discussion, two studies were conducted in classrooms in which an online discussion board was used as an adjunct to traditional classroom teaching. The discussion board was set up as an external communication resource to extend learning activities beyond the classroom and was designed to be aesthetically pleasing and user friendly. With the agreement of instructors, the online discussion activities were facilitated by both instructors and students. The discussion board contained pre-structured discussions which attempted to balance a clear taskorientation with adequate self-direction. Moreover, in the present studies all online discussion activities were associated with class assignment to ensure a certain degree of relevance.

\section{STUDY 1}

\section{Method}

\section{Participants}

The participants were 91 students from six sections of an undergraduate instructional technology course at a large Midwestern university. These sections were taught by different instructors, but all sections followed the same instructional content and schedule, with three sections being taught during the month of June and three sections during the month of July. Students received a small amount of course credit for participating in the study. The sample included 14 males and 77 females; 7 juniors, 75 seniors, and 9 graduate students. The age range was 20 to 58 years.

\section{Measures}

Motivation-Intrinsic motivation was measured by Deci and Ryan's Intrinsic Motivation Inventory (IMI) which had been used in several studies of intrinsic motivation and self-regulation (Self-Determination Theory WWW). The IMI was modified to specifically address participation in the online discussion forum in this study. The 23 questions include seven measuring perceived value/usefulness of the online discussion $(\alpha=.95)$, eight measuring interest/enjoyment in online discussion $(\alpha=.96)$, and eight measuring feelings of self-determination in regard to the online discussion $(\alpha=.92)$.

Reasons for Motivation Change-A subset of students who showed relatively large increases or decreases in motivation completed an additional questionnaire which contained 12 Likert-style items and one open-ended item addressing reasons for the changes. There were two versions of this questionnaire, one for motivation increasers and one for motivation decreasers. 
Attitude-Students' attitude toward the class in general was measured by six Likert-style items created for this study.

Computer/Internet Skill—Students' computer/internet skills were self-reported in the demographic information with two Likert-style items created for this study. One item assessed confidence for using a personal computer. The other item assessed confidence for using the Internet to locate information.

Participation-Students' participation in the online discussion board was measured by: 1) number of times logged on; and 2) number of messages posted.

\section{Procedures}

As a normal part of the course, students were required to participate in a discussion board at a certain frequency (see Thomas, 2002, for a discussion of the affects of requiring participation). A single discussion board was open to all sections of the course, so students could view and reply to messages posted by students from all sections. The discussion board was divided into three areas: Chapter Discussions, Projects, and Other Questions or Concerns.

Instructors informed students about the requirement to use the discussion board, and demonstrated its use at the beginning of the semester. During the course, students were required to share ideas, submit assignments and ask/answer questions using the discussion board. The instructors agreed to participate as coordinators. Their tasks included reminding students to meet the required minimum number of posted messages, encouraging the use of the discussion board beyond the minimum requirements, and replying to questions the students could not answer.

Students in the study completed survey questionnaires measuring demographic information, intrinsic motivation for participating in online discussions, and attitude toward the class. In order to track their motivation, the same motivation questionnaire was administered three times: at the beginning, the mid-point and the end of the course. A subset of students who showed relatively large increases or decreases in their level of motivation for online discussion were asked to complete additional questionnaires addressing the reasons for these changes.

\section{Results}

Means, standard deviations, internal consistency coefficients, and sample items for all scales used in the study can be found in Table 1 .

\section{Correlation Analyses}

A series of correlation analyses was performed to analyze how students' participation (number of times logged on, number of messages posted) was related 
STUDENTS' MOTIVATION FOR ONLINE DISCUSSION / 73

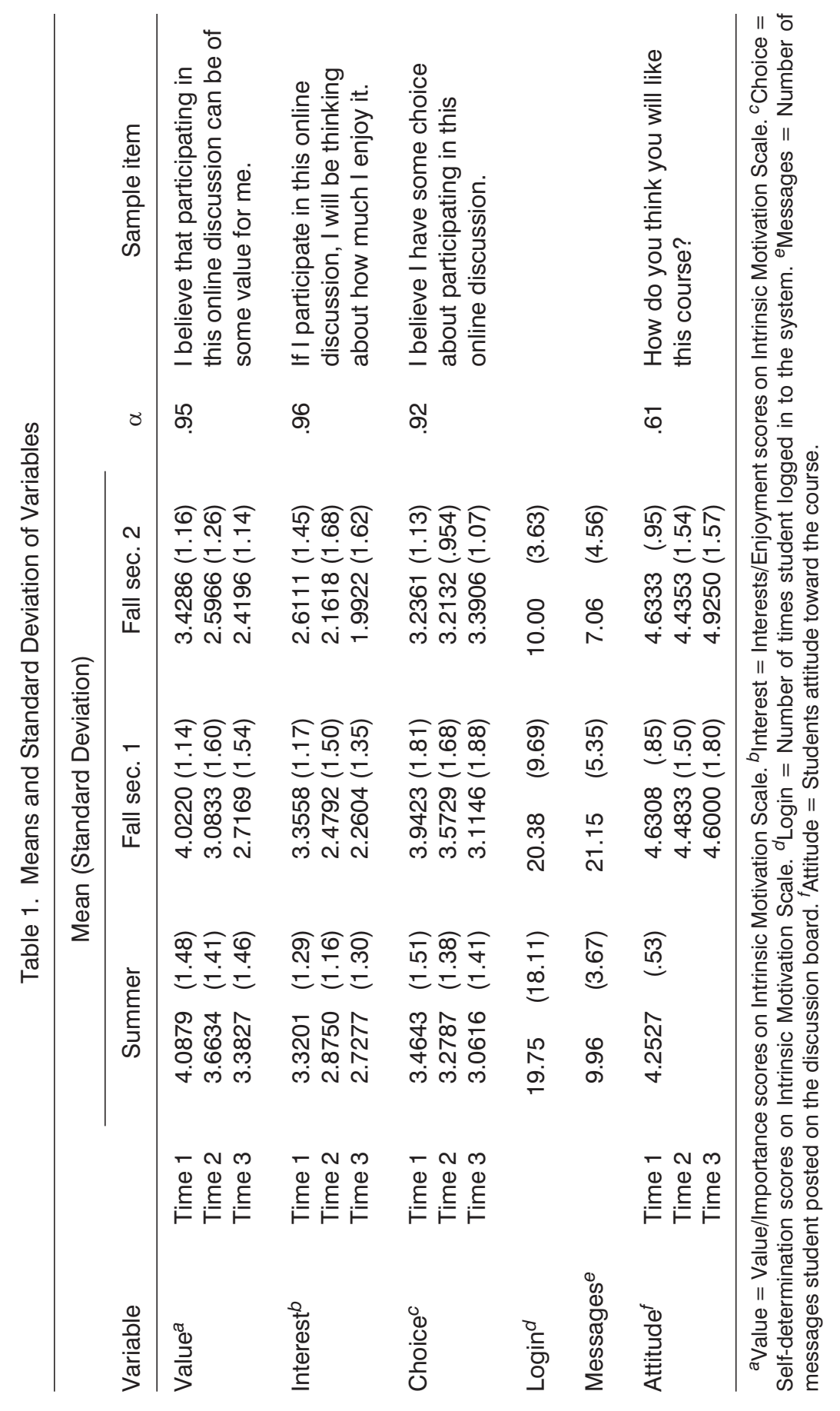


to their intrinsic motivation, computer skills, and attitudes toward the course (see Table 2). In the correlation matrix, the value/usefulness scores for time 2 and 3 , interest/enjoyment scores for time 2 and 3 , and self-determination scores for time 3 were significantly correlated with number of times logged on. Only self-determination scores for time 1 were significantly correlated with number of messages posted. These correlations would be considered modest in magnitude (Cohen, 1977).

Students' attitudes toward the course were significantly related to their intrinsic motivation. No significant correlations were found between students' level of computer skills and any variables of interest.

\section{Changes in Intrinsic Motivation}

To measure changes in students' intrinsic motivation, three repeated measures ANOVAs were conducted on the three intrinsic motivation sub-scores. The results for value/usefulness indicated a significant difference across time $[F(2,164)=18.58 ; p<.001]$. Means indicated value/usefulness fell steadily across time ( $M=4.09$ at time $1, M=3.66$ at time 2 , and $M=3.38$ at time 3$)$. The results for interest/enjoyment also indicated a significant difference across time $[F(2,164)=15.08 ; p<.001]$. Means indicated that interest/enjoyment fell steadily across time ( $M=3.32$ at time $1, M=2.88$ at time 2 , and $M=2.73$ at time 3$)$. Changes across time for self-determination were non-significant.

Follow-up paired $t$-tests using an adjusted alpha of .008 revealed significant differences between times 1 and $2[t(91)=4.41, p<.001]$, and between times 1 and $3[t(91)=5.46, p<.001]$ on the value/usefulness score. There were significant differences between times 1 and $2[t(91)=4.00, p<.001]$ and between times 1 and 3 on the interest/enjoyment score $[t(91)=4.87, p<.001]$. Results are illustrated in Figure 1.

\section{Reasons for Changes in Motivation}

To explore possible reasons for changes in students' level of motivation across time, 18 students showing particularly large increases in motivation over time, and 47 students showing particularly large decreases in motivation over time were asked to complete motivation change questionnaires. Student responses to the open-ended questions on the survey were coded by two different reviewers individually. Themes were identified based on the agreement of the reviewers.

Increasers-Means for the reasons provided to the students who reported motivation increases ranged from 2.68 to 4.51 on a 7 -point scale. Reasons with means greater than 4 included: 1) their computer competency had improved $(M=4.21)$; 2) they were more familiar with the online discussion environment $(M=4.51 ; 3)$ the feedback from their instructors $(M=4.24) ; 4)$ their attitude 


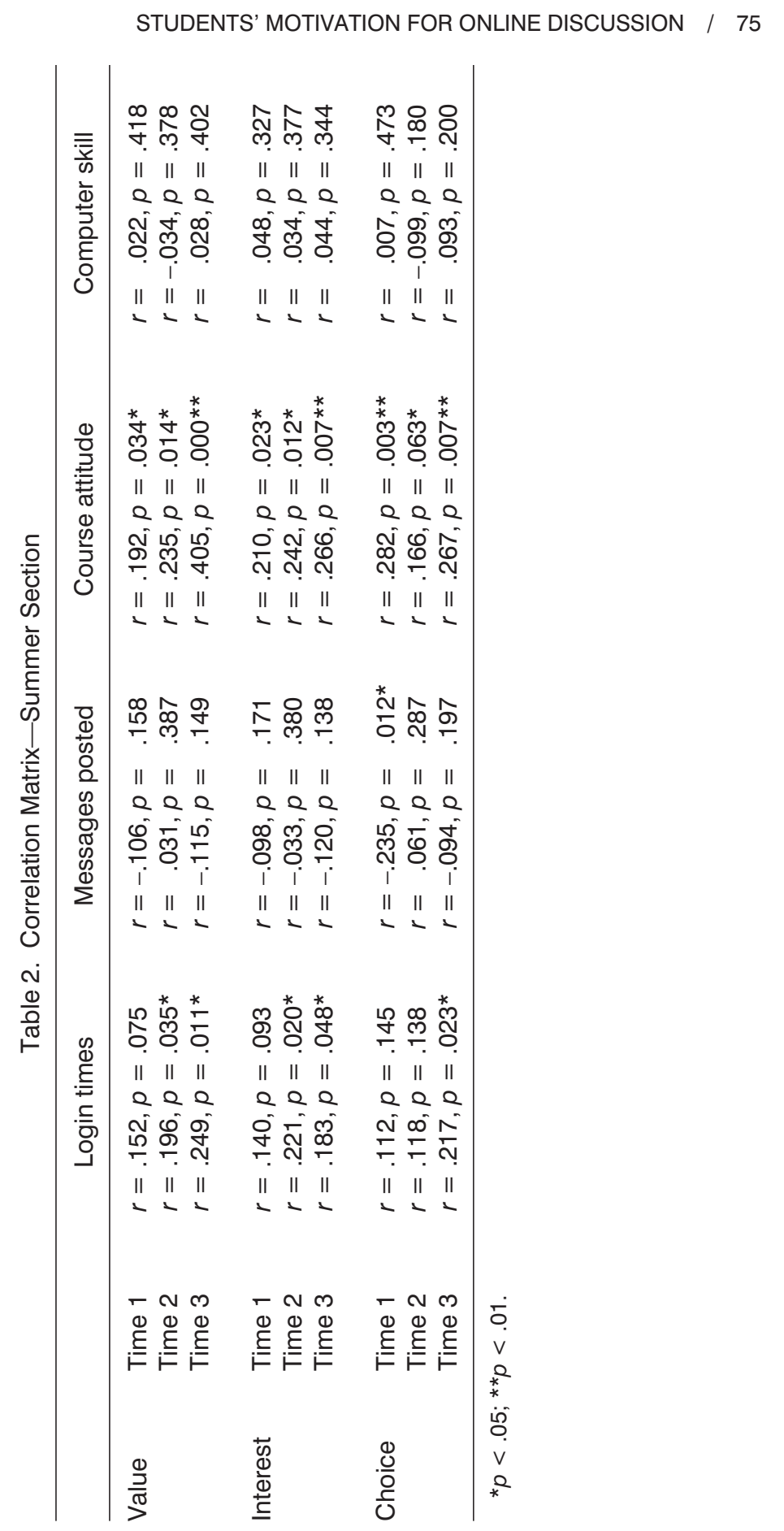


76 / XIE, DEBACKER AND FERGUSON

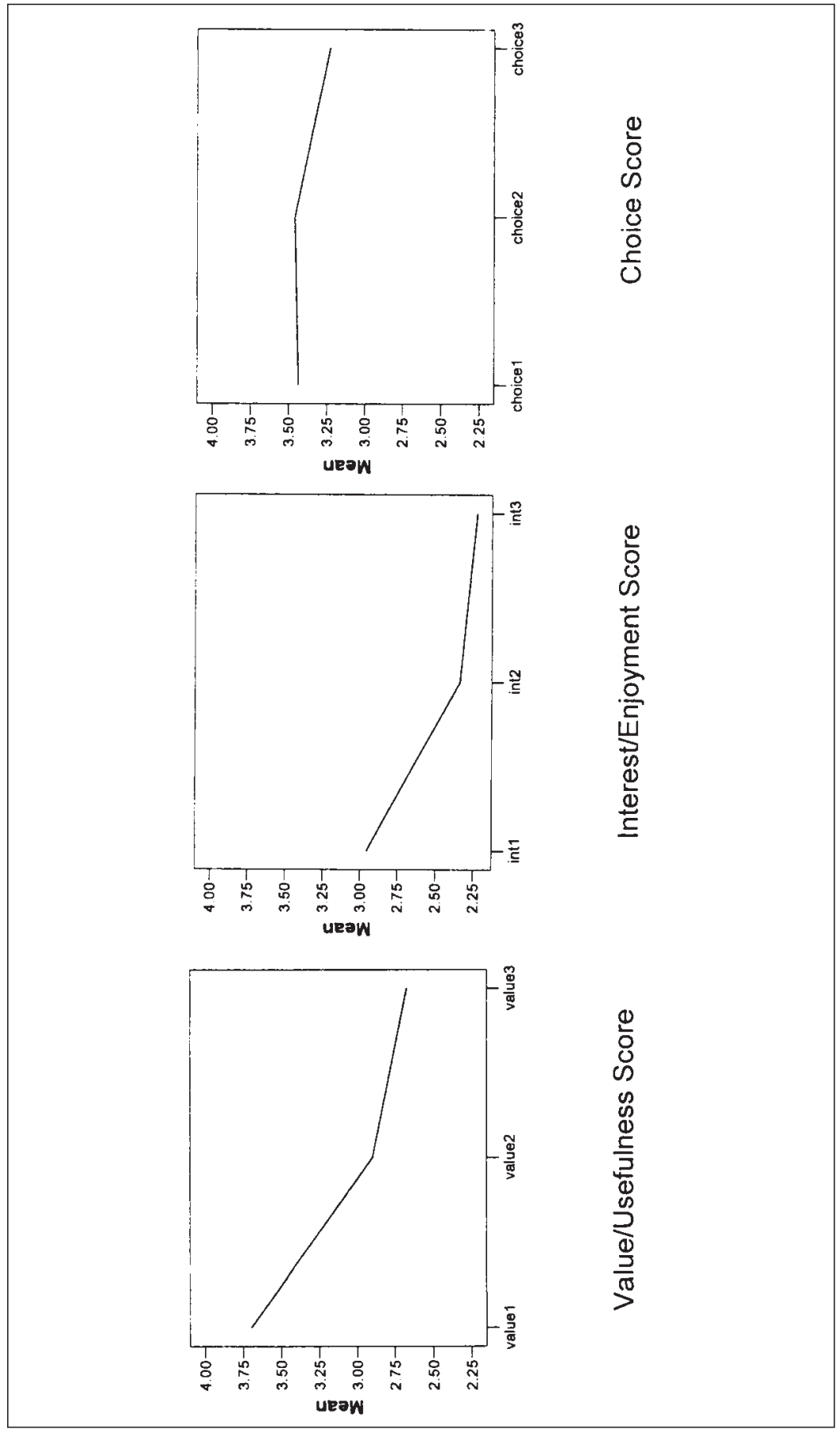

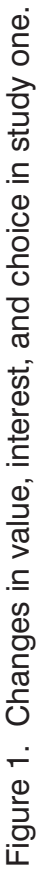


toward the course changed $(M=4.12)$; and 5) the topics on the discussion board became more practical $(M=4.43)$. These students usually did not respond to open-ended questions.

Decreasers - None of the means for the reasons provided to the students who reported motivation decreases were higher than 4.0 on a 7-point scale. The open-ended questions reflected that students believed the motivation decreases were due to: 1) feeling rushed and not having sufficient time for participating in the online discussion $(n=13) ; 2)$ the participation was mandatory and students did not have a choice but to post messages on the discussion board $(n=4)$; and 3 ) not finding it necessary to communicate on the online discussion board $(n=3)$.

\section{Discussion}

Over time, students' intrinsic motivation for participating in online discussion dropped steadily. Our attempt to understand the reasons for changes in motivation was only partially successful. Some of the reasons provided on the motivational increase questionnaire were endorsed by the students, but the reasons on the motivational decrease questionnaire were not strongly endorsed. Open-ended responses generally pointed to lack of time as a primary reason for decreases in motivation. Students felt overwhelmed by the course workload and did not feel they had enough time to elaborate their thoughts and ideas in online discussion. Motivation decreases may also have been due to the nature of the one month summer class format in which students and instructors met four times a week, allowing ample opportunity to communicate with each other face-to-face. As a result, students reported it was not necessary to communicate via this electronic method. We wondered if the same findings would occur over the course of the regular 16-week semester.

\section{STUDY 2}

In order to confirm the findings from Study 1 and to further explore: a) reasons that affected students' motivation to participate in online discussion in the classroom teaching settings; and b) the extent to which time constraints affects the findings reported in Study 1, we partially redesigned Study 1 and conducted Study 2 in a regular 4-month semester.

\section{Method}

\section{Participants}

The participants were 32 students from two sections of an undergraduate instructional technology course at a large Midwestern university. Students received a small amount of course credit for participating in the study. The sample 
included 4 males and 28 females; 3 juniors, 28 seniors, and 1 graduate student. The age range was 20 to 24 years.

\section{Measures and Procedures}

Study 2 employed the same measures of demographic information, motivation, and class attitude described in Study 1. In place of the motivation change questionnaires, students showing changes in motivation were interviewed about those changes.

The major differences between Study 1 and 2 were: 1) In contrast to Study 1, the participants were from sections being taught during a regular four-month-long semester. In Study 2, students did not meet everyday in class, meaning time constraints may have been reduced and there may have been increased value for the online discussion board. 2) In order to better understand the reasons for changes in students' motivation, students who showed significant increases or decreases in their level of motivation for online discussion were interviewed by the investigators individually to identify reasons for the change. 3) To gain more insight into the role of online discussion in each class setting, the instructors were interviewed at the midpoint of the semester.

Interviews with students and instructors followed a structured interview protocol and were recorded using a digital voice recorder. In addition, interview note-taking forms were prepared for use during the interview. After data collection, the interviews were transcribed verbatim for later analysis.

\section{Results}

\section{Correlation Analyses}

A series of correlation analyses ${ }^{1}$ was performed to analyze how students' participation (Number of times logged on, number of messages posted) was related to their intrinsic motivation, computer skills, and attitudes toward the course. Because interviews revealed that the two instructors had very different attitudes toward the inclusion of online discussion in the course, and applied different participation requirements in their classes, the two sections were analyzed separately. The instructors' attitude and course policy differences will be discussed in a later section of the article.

In the correlation matrix for section 1 (see Table 3), the value/usefulness scores for all three times and interest/enjoyment scores for all three times were significantly correlated with the number of time logged on, but self-determination scores were not. The value/usefulness scores for all three times and interest/enjoyment

\footnotetext{
${ }^{1}$ Data screening revealed three outliners with login scores of 133,120 , and 88 (group mean $=$ 23.12). These outliers were removed from further analysis.
} 


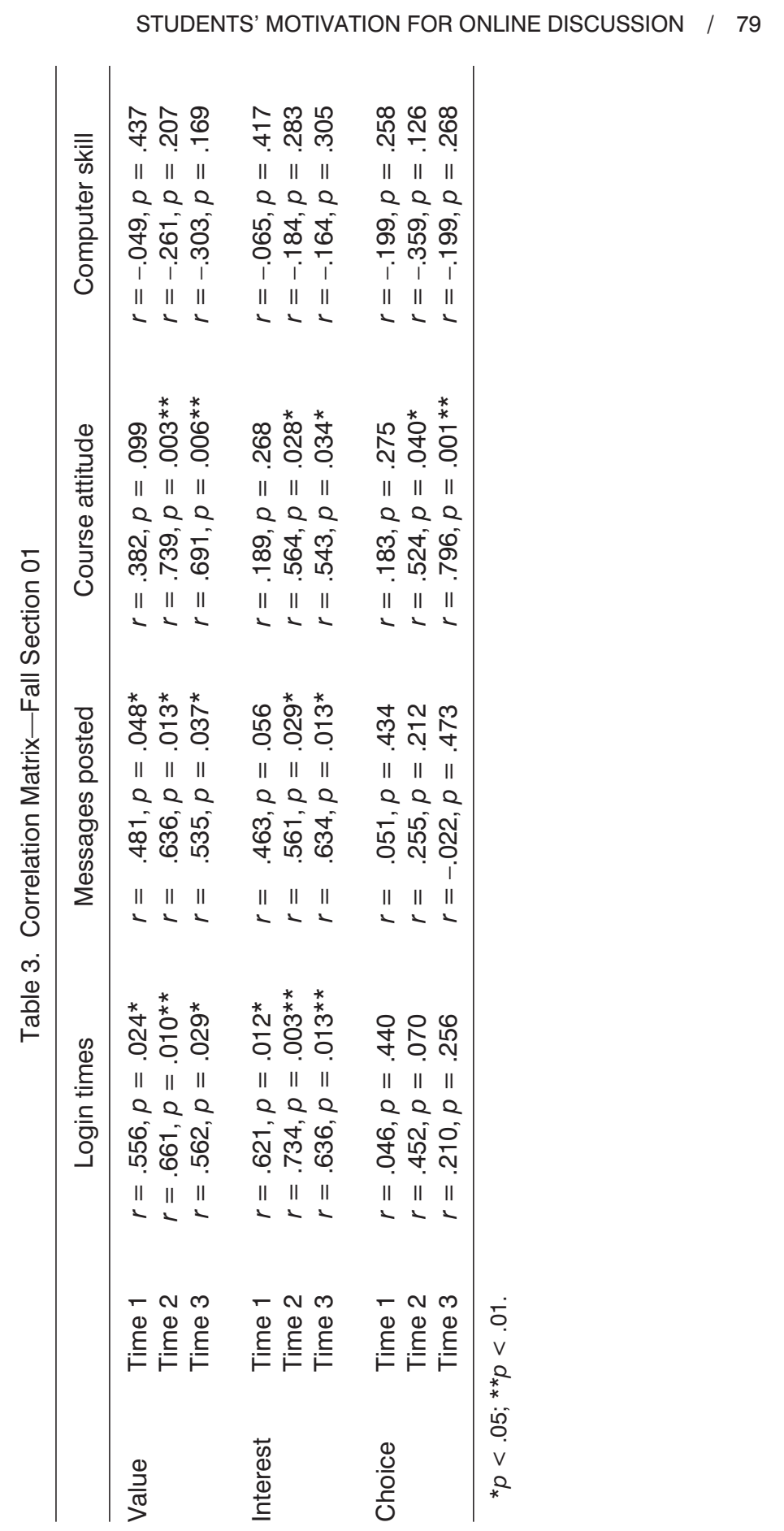


scores for time 2 and 3 were significantly correlated with the number of messages posted, but self-determination scores were not. All three intrinsic motivation subscale scores were significantly correlated with course attitude scores for time 2 and 3. All of these correlations are considered to be large in magnitude (Cohen, 1977).

In the correlation matrix for section 2 (see Table 4), the value/usefulness scores for time 2 and 3, interest/enjoyment scores for time 2, self-determination scores for time 1 and 2 were significantly correlated with the number of time logged on. No significance was found between intrinsic motivation subscales and number of messages posted. Value/usefulness scores for time 1 and 2, interest/enjoyment scores for time 2, and self-determination scores for time 2 were significantly correlated with course attitude scores. All of these correlations are considered to be moderate or large in magnitude (Cohen, 1977).

In both classes, no significant correlations were found among number of times logged on, students' level of computer skills, and course attitude scores. No significant correlations were found among computer/internet skills and intrinsic motivation scores.

\section{Difference between Classes}

A series of independent $t$-tests was conducted to compare sample means on all variables of interest between the two classes. Differences were found on student login times $[t(29)=4.18, p<.001]$ and the number of messages posted $[t(29)=7.90, p<001]$. Means for student login times are $M=20.38, S D=9.691$ for section $1, M=10, S D=3.63$ for section 2. Means for number of messages posted are $M=21.15, S D=5.35$ for section $1, M=7.06, S D=4.56$ for section 2 . No significant differences were found on the three intrinsic motivation subscales or the course attitude scores.

\section{Changes in Intrinsic Motivation}

To measure changes in students' intrinsic motivation, three repeated measures ANOVAs were conducted on the three intrinsic motivation sub-scores. Since no significant differences were found in motivation scores between two sections, we conducted the ANOVAs on the whole dataset. The results for value/usefulness indicated a significant difference across time $[F(2,60)=12.9 ; p<.001]$. Means indicated value/usefulness fell steadily across time $(M=3.63$ at time $1, M=2.84$ at time 2, and $M=2.67$ at time 3$)$. The results for interest/enjoyment also indicated a significant difference across time $[F(2,60)=9.31 ; p<.001]$. Means indicated that interest/enjoyment fell steadily across time $(M=2.93$ at time $1, M=2.29$ at time 2, and $M=2.23$ at time 3). Changes across time for self-determination were non-significant.

Follow-up paired $t$-tests using an adjusted alpha of .008 revealed significant differences between times 1 and $2[t(31)=3.80, p<.001]$, and between times 1 


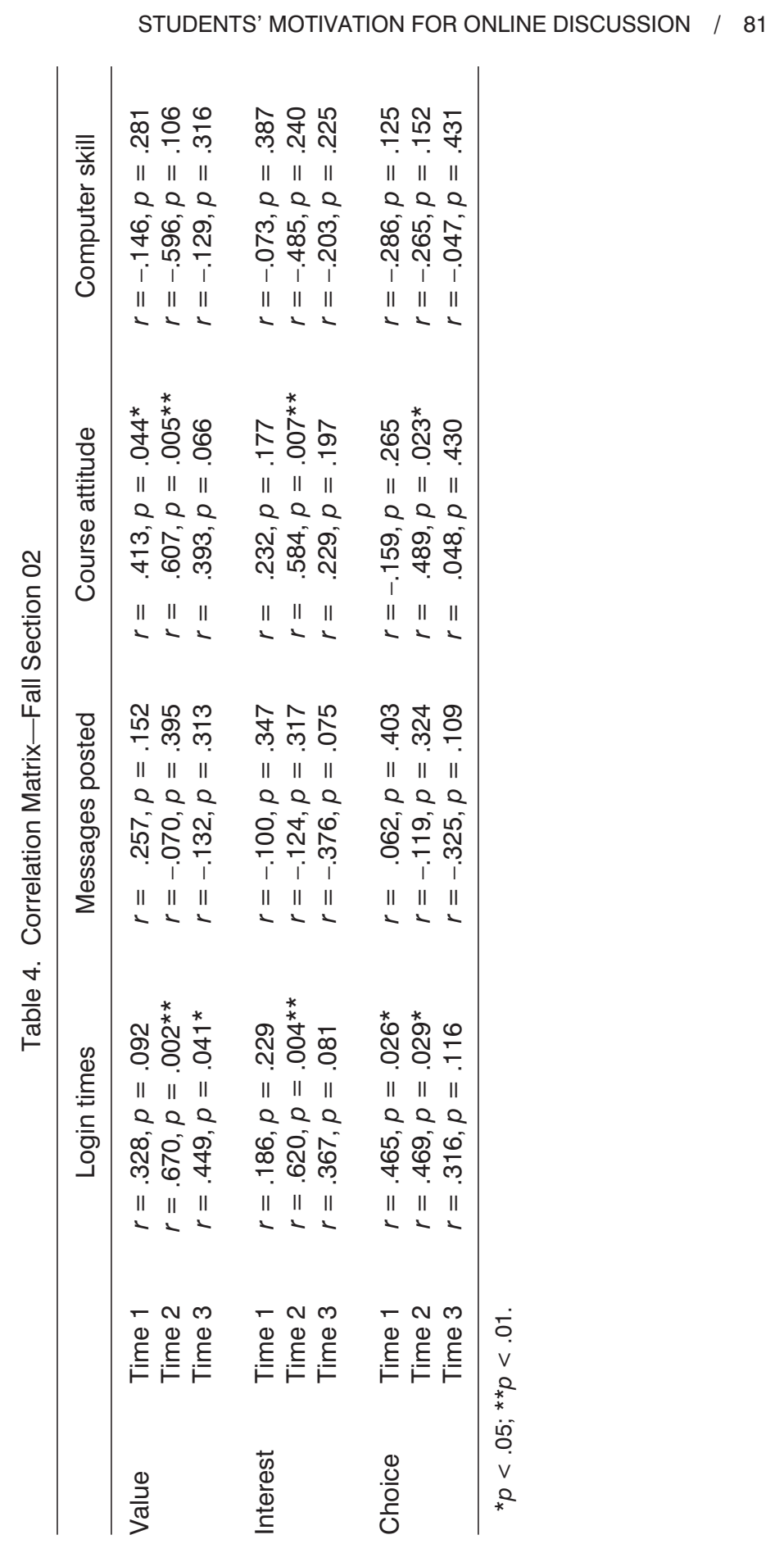


and $3[t(30)=4.73, p<.001]$ on the value/usefulness score. There were significant differences between times 1 and $2[t(31)=3.15, p<.005]$, and between times 1 and 3 on the interest/enjoyment score $[t(30)=3.86, p<.001]$. Results are illustrated in Figure 2.

\section{Reasons for Changes in Motivation}

Instructor and student interviews were transcribed into text format. Open coding on the transcriptions was conducted using Nvivo software. Emerging categories and themes were found and summarized.

Instructor Interviews - The instructor interview revealed each instructor's policy and attitude regarding the online discussion board associated with their class. One instructor reported a very positive attitude toward the online discussion. He believed that the online discussion was an effective strategy to extend learning outside of the classroom, stating: "It allows students processing time, andspeaking for myself-I like to think a lot before I talk, and so it's reaching those kinds of students that process slowly, or at least deliberately, and so they can think about what it is they are going to say, as opposed to discussion in a classroom, where it is more spontaneous and off the cuff, and so that aspect, I like." He also mentioned that the online discussion board allowed students to process information and reflect more deeply. Moreover, this instructor noticed that the discussion board worked very well in his class.

The other instructor did not see the online discussion as really beneficial for the on-site class. He believed it represented an added burden on students, stating: "Although I recognize there is some benefit to writing and reflection there, but in my mind, it doesn't [sic]. In terms of balancing the extra pain in the neck with the possible reflection that some of the students will get, you know, I go for rather not using it."

These different attitudes between the two instructors led them to have different instructional policies and strategies for using the online discussion board. The first instructor used the participation requirement in his class to encourage students' participation in the discussion. He explained his policy, "I assigned each group to a chapter, and then they were responsible for generating the initial questions that get posted onto the discussion board. And then I would go through and read their comments and their summaries, and if that prompted a question from me, then I would also enter questions inside of there. And try to probe them deeper." He was actively involved in the online discussion as well. He believed "the best strategy is to let students know whether or not the instructor appears to be involved in the discussion, and is facilitating. When that happens, then there is more interaction with the students, and their responses are more with higher quality." The other instructor, on the other hand, believed that giving more freedom to students might give them more opportunity to express their ideas. As 


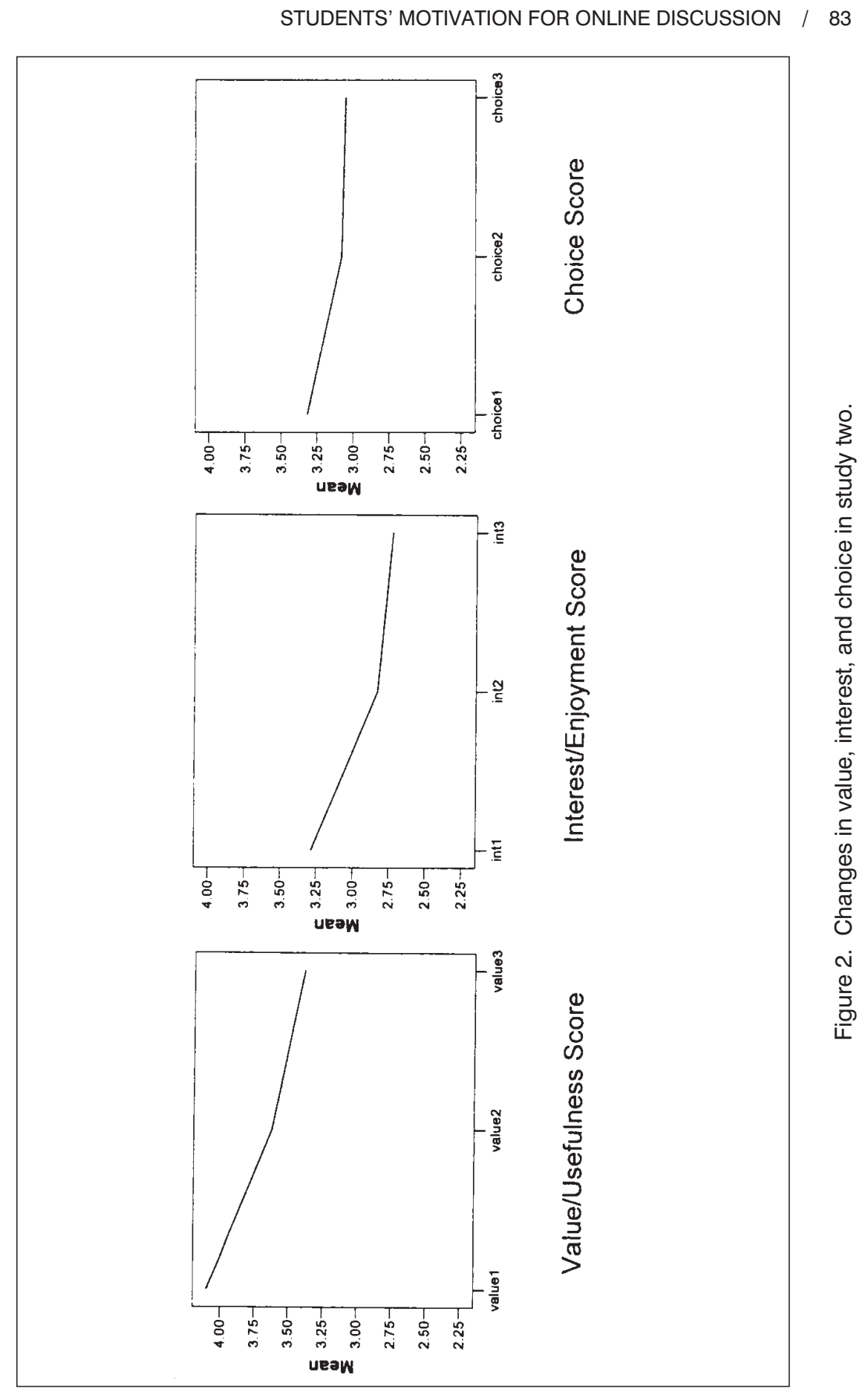


a result, he de-emphasized the course requirement policy in his class and did not involve himself in the online discussion.

Student Interviews - Students reported on factors that influenced their motivation to participate in the online discussion associated to the course. From the interview data, we identified the following themes.

1. Instructor's role in discussion. Most students believed that instructors' participation, guidance and feedback in the online discussion were critical to their motivation to participate in the discussion. When instructors were participating in the online discussion, students felt their participation was monitored by instructors and had more motivation to participate, possibly leading to a higher participation rate and higher performance quality. The students who decreased in their motivation level reported that they perceived less involvement of their instructor. Without the instructor's involvement in the online discussion, students felt more unmotivated and less interested.

2. Interaction between peers. Most students also believed that peer interaction in the online discussion was another important factor that could influence their motivation to participate in the discussion. By interacting with peers, students can see many different opinions, especially on some controversial topics. Different voices could raise their interests in the discussion.

3. Discussion topics. Students reported different opinions regarding the topics they like to discuss in the online discussion board. Most students who showed increases in their motivation level reported that they liked to discuss course-related topics and believed those topics were beneficial for expanding their knowledge for their class. On the other hand, students who showed decreased motivation reported they would like to discuss self-generated topics because those topics were interesting and related to their life more closely. However, we counted the number of messages posted concerning these two areas (course-related vs. self-generated) and found that the number of messages posted on course-related topics was significantly greater than the one on self-generated topics, and most interactions and discussions were focused on course-related topics. This might also be a reason for students' motivation changes. Students who preferred task-oriented topics had more interaction with other students and the instructor in the online discussion and perceived greater importance and value of the online discussion. Students who preferred self-generated topics did not get feedback from others which might have led them to perceive less importance and value of the online discussion.

4. Course requirements. On the issue of whether it is necessary to associate the online discussion with course assignments, students expressed different opinions. Students who showed increased motivation reported that they would prefer to have a participation requirement as it provided a clear understanding of expectations for online discussion. Other students believed that the participation requirement was overly controlling. This feeling of lack of autonomy promoted only the minimum amount of participation students felt was necessary for completing 
tasks and earning a good grade. They did not really engage in the online discussion. Therefore, they believed the participation requirement had negative effects on their intrinsic motivation to participate in the discussion.

Since the two instructors had different attitudes toward participation in their classes (one emphasized participation, the other did not), we compared the number of messages posted and the number of login times by the students in these two sections. Significant differences were found, in that the participation rate in the section that emphasized participation was higher than in the section that did not emphasize participation. (Mean for number of messages are: $M=21.15$ for section $1, M=7.06$ for section 2; mean for login times are: $M=20.38$ for section $1, M=10.00$ for section 2.) It is important to note that the common participation policy required students to post a minimum of 12 messages (hence, logging on 12 times). The section that emphasized participation had a participation rate that clearly exceeded the minimum requirement, while the section that did not emphasize participation had a participation rate that fell below the minimum requirement.

5. System functions. The usability of the system was also reported on as an important factor that could affect participation. In the present study, the discussion board was set up with well-structured forums, quoting function, grouping interaction, and easy navigation function. These functions were reported to have increased the interest of those participating in the online discussion.

\section{General Discussion}

The purpose of this study was to investigate the relationship between students' intrinsic motivation and other critical issues related to participating in online discussion. The findings provided evidence that students' participation in online discussion was related to their intrinsic motivation. That is, if students perceived the online discussion as valuable, interesting, and enjoyable, they were more likely to participate in the online discussion. These findings support the hypothesis of SDT (Deci \& Ryan, 1985) that people who find a task intrinsically motivating show high levels of engagement. However, in our findings, students' self-reported computer or Internet skills were not related to their participation in online discussion. This seems to be at odds with SDT which proposes that people's perceived competence is one of the three innate psychological needs related to intrinsic motivation. A possible explanation might be that the computer or Internet skills required for participation were elementary and all the students perceived that they had high competence $(M=6.25$ for their computer or Internet skills on a 7-point scale). Student interviews also supported this argument. They reported that the discussion board was set up with well-structured forms with multiple user friendly functions which enabled them to operate the discussion board easily, and some of the functions, such as quoting and voting, introduced some level of interest to their participating in the online discussion. 
We also discovered that students' intrinsic motivation for online discussion was highly related to their attitudes toward the course. That is, if students perceived the course itself to be interesting and valuable, they also perceived the online discussion activities in the course as interesting and valuable. This suggests that instructors should foster a positive class climate and help students to establish positive attitudes toward the course to increase or maintain their motivation for participating in online discussions.

Over time in all sections, both students' interest in and perceived value for participating in online discussion dropped steadily. This finding is similar to those of other studies of achievement motivation that report steady declines in motivation across a semester or academic year (DeBacker \& Miller, 2004; Stipek \& Ryan, 1997; Wigfield \& Eccles, 2000). Furthermore, one aspect of intrinsic motivation is interest. Interest is known to be related to novelty (Ryan \& Deci, 2000b). To the extent that participating in online discussion became less novel over time, intrinsic motivation may have waned. Other reasons for the decrease in motivation could be found in our student interviews. Students commonly mentioned lack of facilitation by the instructor and lack of peer responses to their postings as reasons for their declines in motivation.

Our findings suggested that the instructor's attitude and policy were important factors that influenced students' participation in the online discussion activities. Although significant differences were not found in intrinsic motivation between the two Fall classes, we did find significant differences on student participation rates in the online discussion. That is, in the section in which the instructor more highly valued the online discussion and explicitly encouraged participation, the students had a much higher number of login times and messages posted than in the section in which the instructor expressed less valuing of the online discussion and de-emphasized participation.

It is also interesting to note that the instructor's attitude and policy appears to have affected the correlation between students' value and interest, and their participation and course attitudes. Relationships among these variables were stronger in the section where there was a positive instructor attitude and an explicit course policy. These stronger correlations seem to suggest that, with instructor emphasis on the value of online discussion, explicit course requirements, and active participation in the discussion, students perceive the online discussion as valuable and interesting, and will persist in participating. The student interviews also supported this point. Many students reported that they believed the instructor's participation, guidance, and feedback in the online discussion were critical for motivating them to participate in the online discussion and helping them to perceive the value of this activity. Some students also reported that the explicitly stated course requirements provided clear rules and guidelines for them to participate in the online discussion. However, it is also possible that the higher correlations found in section 1 were an artifact of the greater sample size and 
variability of scores compared to section 2. More research is needed to further explore these relationships.

The weaker relationship between choice and participation in this same section indicates that the more stringent enforcement of the course requirement may have undermined students' perceived autonomy. On the other hand, students' rate of participation was nearly twice the minimum requirement. Students were apparently not responding solely to the extrinsic force. This made us wonder what motivated the students to participate beyond the minimum requirement. An explanation might be that the instructors' policy and attitude resulted in students perceiving more interest and value in the activities. The apparent benefit of using a participation requirement to promote interest and perceived value, and ensure participation, seemed to offset any negative influence of introducing that extrinsic control.

Moreover, the student interviews indicated that peer interactions in the online discussions contributed to their positive attitude. Especially in regard to controversial topics, students could raise different opinions, which promoted their interest in the online discussion itself. Although students differed in their opinions about whether discussion topics should be assigned or self-generated, most of the interactions between students addressed course-assigned topics. This is consistent with findings of previous studies (Benfield, 2002; Horton, 2000; Jeong, 2003; Ronteltap \& Eurelings, 2002).

\section{CONCLUSIONS}

This article demonstrated that students' motivation is related to their participation in the online discussion and discovered many factors that influence students' motivation for participating in the online discussion. Our findings have several implications for educators. First, the instructor should demonstrate a positive attitude toward online discussion when they decide to include it as a class activity. Clearly stated course requirements and participation guidelines should be provided to the students. Moreover, well-designed discussion topics related to the instructional content should be developed as guiding topics for students to explore. Second, the instructor should foster a positive class climate to promote students' continued interest in the online discussion activity. The instructor should also emphasize the value of the online discussion activities explicitly to the class to help students recognize the value of participating. Third, the instructor should get involved in the online discussion and guide students' interactions. Students' feedback to each other should be encouraged. Finally, an easy-to-use discussion board tool should be selected. Multiple functions, such as grouping, quoting, voting, and so on, could promote more interest in participating.

To follow up these findings and more fully understand the potential effectiveness of online discussion, we propose several extensions of our study. First, an experimental design could be used to explore the instructor's influence on the 
effectiveness of online discussion. Second, to explore the nature of students' interactions in the discussion board in more depth, a qualitative approach could be taken to the analysis of the content of online discussions. Moreover, investigations of students' motivation for online discussion in other settings, such as distance learning courses, could be conducted to extend our understanding of online communication.

\section{REFERENCES}

Aragon, S. R., Johnson, S. D., \& Shaik, N. (2002). The influence of learning style preferences on student success in online versus face-to-face environments. The American Journal of Distance Education, 16(4), 227-244.

Benbunan-Fich, R., \& Hiltz, S. R. (1999). Impacts of asynchronous learning networks on individual and group problem solving: A field experiment. Group Decision and Negotiation, 8, 409-426.

Benfield, G. (2002). Designing and managing effective online discussions. Oxford Centre for Staff and Learning Development, OCSLD.

Cohen, J. (1977). Statistical power analysis for the behavioral sciences. New York: Academic Press.

DeBacker, T. K., \& Miller, R. B. (2004). Perceptions of classroom climate, student motivation, and achievement: Changes and interrelationships across an academic year. Paper presented at the Ninth International Conference on Motivation, Lisbon, Portugal.

Deci, E. L., \& Ryan, R. M. (1985). Intrinsic motivation and self-determination in human behaviors. New York: Plenum.

Deci, E. L., \& Ryan, R. M. (2000). The "what" and "why" of goal pursuits: Human needs and the self-determination of behavior. Psychological Inquiry, 11(4), 227-268.

Diaz, D. P., \& Cartnal, R. B. (1999). Students' learning styles in two classes. College Teaching, 47(4), 130-135.

Deumer, L., Fontenot, D., Gumfory, K., Kallus, M., Larsen, J., Shafer, S., \& Shaw, B. C., Jr. (2002). The use of online synchronous discussion groups to enhance community formation and professional identity development. Journal of Interactive Online Learning, 1(2). Retrieved January 20, 2004, from http://www.ncolr.org/jiol/issues/PDF/1.2.4.pdf.

Hara, N., Bonk, C. J., \& Angeli, C. (2000). Content analysis of online discussion in an applied educational psychology course. Instructional Science, 28, 115-152.

Horton, W. (2000). Designing web-based training. New York: John Wiley \& Sons, Inc.

Howland, J. L., \& Moore, J. L. (2002). Student perceptions as distance learners in internet-based courses. Distance Education, 23(2), 183-195.

Jeong, A. C. (2003). The sequential analysis of group interaction and critical thinking in online threaded discussions. The American Journal of Distance Education, 17(1), $25-43$.

Liu, Y. (2002). What does research say about the nature of computer-mediated communication: Task-oriented, social-emotion-oriented, or both? Electronic Journal of Sociology, 6(1). Retrieved January 20, 2004 from http://www.sociology.org/content/vol066.001/liu.html 
McDuffie, A. R., \& Slavit, D. (2003). Utilizing online discussion to support reflection and challenge beliefs in elementary mathematics methods classrooms. Contemporary Issues in Technology and Teacher Education, 2(4), 446-466.,

Murphy, E. (2004). Recognising and promoting collaboration in an online asynchronous discussion. British Journal of Educational Technology, 35(4), 421-431.

Neuhauser, C. (2002). Learning style and effectiveness of online and face-to-face instruction. The American Journal of Distance Education, 16(2), 99-113.

Ronteltap, F., \& Eurelings, A. (2002). Activity and interaction of students in an electronic learning environment for problem-based learning. Distance Education, 23(1), 11-22.

Ryan, R. M., \& Deci, E. L. (2000a). Intrinsic and extrinsic motivations: Classic definitions and new directions. Contemporary Educational Psychology, 25, 54-67.

Ryan, R. M., \& Deci, E. L. (2000b). Self-determination theory and the facilitation of intrinsic motivation, social development, and well-being. American Psychologist, 55(1), 68-78.

Self-Determination Theory WWW Intrinsic Motivation Inventory. (n.d.). Retrieved January 20, 2004, from http://www.psych.rochester.edu/SDT/measures/intrins.htm

Spencer, D. H., \& Hiltz, S. R. (2003). A field study of use of synchronous chat in online courses. Paper presented at the 36th International Conference on System Sciences, Hawaii.

Stipek, D., \& Ryan, R. (1997). Economically disadvantaged preschoolers: Ready to learn but further to go. Developmental Psychology, 33(4), 711-723.

Thomas, M. J. W. (2002). Student participation in online discussion: The implications of learning activities and discourse development on assessment. Paper presented the Evaluations 2002 conference, Brisbane, Queensland.

Warschauer, M. (1996). Comparing face-to-face and electronic discussion in the second language classroom. CALICO Journal, 13(2), 7-26.

Wigfield, A., \& Eccles, J. S. (2000). Expectancy-value theory of achievement motivation. Journal of Contemporary Educational Psychology, 25, 68-81.

Yildiz, S., \& Bichelmeyer, B. A. (2003). Exploding electronic forum participation and interaction by efl speakers in two web-based graduate-level courses. Distance Education, 24(2), 175-193.

Zhang, D., \& Mu, A. (2003). Use of online chat in a webct-enhanced elementary Chinese language class. Paper presented at the World Conference on E-Learning in Corp., Govt., Health., \& Higher Ed., Phoenix, AZ.

Direct reprint requests to:

Kui Xie, M.Ed.

Dept. of Educational Psychology

University of Oklahoma

820 Van Vleet Oval

Norman, OK 73019-2041

e-mail: xiekui@ou.edu 